\title{
A Hidden Coordination-Bond Torsional Deformation as a Sign of Possible Spin Transition in Nickel(II)-Bis(nitroxide) Compounds
}

\author{
Yukiya Kyoden and Takayuki Ishida *(D) \\ Department of Engineering Science, The University of Electro-Communications, Chofu, Tokyo 182-8585, Japan; \\ kyoden@ttf.pc.uec.ac.jp \\ * Correspondence: takayuki.ishida@uec.ac.jp; Tel.: +81-42-443-5490; Fax: +81-42-443-5501
}

Academic Editor: Gotzone Barandika

Received: 26 July 2020; Accepted: 18 August 2020; Published: 20 August 2020

check for updates

\begin{abstract}
Complex formation of nickel(II) tetrafluoroborate and tert-butyl 5-phenyl-2-pyridyl nitroxide (phpyNO) in the presence of sodium cyanate gave a discrete molecule $\left[\mathrm{Ni}(\text { phpyNO })_{2}(\mathrm{X})_{2}\right](\mathrm{X}=\mathrm{NCO})$. The Ni-O-N-C $\mathrm{C}_{\mathrm{sp}} 2$ torsion angles were reduced on heating; $33.5(5)^{\circ}$ and $36.2(4)^{\circ}$ at $100 \mathrm{~K}$ vs. $25.7(10)^{\circ}$ and $32.3(11)^{\circ}$ at $400 \mathrm{~K}$. The magnetic behavior was almost diamagnetic below ca. $100 \mathrm{~K}$, and the $\chi_{\mathrm{m}} T$ value reached $1.04 \mathrm{~cm}^{3} \mathrm{~K} \mathrm{~mol}^{-1}$ at $400 \mathrm{~K}$. An analysis using the van't Hoff equation indicates a possible spin transition at $T_{1 / 2}>>400 \mathrm{~K}$. Density functional theory calculation shows that the singlet-quintet energy gap decreases as the structural change from 100 to $400 \mathrm{~K}$. The geometry optimization results suggest that the diamagnetic state has the Ni-O-N-C $\mathrm{C}_{\mathrm{sp}} 2$ torsion angles of $32.7^{\circ}$ while the $S_{\text {total }}=2$ state has those of $11.9^{\circ}$. The latter could not be experimentally observed even at $400 \mathrm{~K}$. After overviewing the results on the known $\mathrm{X}=\mathrm{Br}, \mathrm{Cl}$, and NCS derivatives, the magnetic behavior is described in a common phase diagram. The $\mathrm{Br}$ and $\mathrm{Cl}$ compounds undergo the energy level crossing of the high-/low-spin states, but the NCS and NCO compounds do not in a conventional experimental temperature range. The spin transition mechanism in this series involves the exchange coupling switch between ferro- and antiferromagnetic interactions, corresponding to the high- and low-spin phases, respectively.
\end{abstract}

Keywords: aminoxyl; spin transition; exchange interaction; magneto-structural relation

\section{Introduction}

Coordination compounds provide us a great opportunity for the development of spin-transition materials [1-8]. Magnetic switches are needed for applications in display, memory, sensor, and related smart devices. Iron(II) $\left(3 d^{6}\right)$-based spin-crossover (SCO) materials are the most intensively studied [9-14], because magnetic and chromic changes would be drastic between the low-spin (LS) $S=0$ diamagnetic and high-spin (HS) $S=2$ paramagnetic states. Furthermore, much attention has been paid to SCO near room temperature required for applications under ambient conditions.

In the context of frontier orbital engineering, heterospin systems have an advantage in the wide diversity of paramagnetic centers and practically infinite combinations and mutual geometries. Organic radical species can also be applied to spin sources [6-8], and ligands can serve not only as a cap, bridge, or polyhedron regulator, but also as a spin carrier. According to the "metal-radical approach" proposed by Gatteschi et al. $[15,16]$, direct metal-radical coordination bonds afford considerable magnetic exchange interaction. A number of ligands based on 2-azaaryl tert-butyl nitroxides (aminoxyls) have been explored for $2 p-3 d$ [17-23] as well as $2 p-4 f$ heterospin systems [24-28]. The exchange coupling in radical-coordinated copper(II) $\left(3 \mathrm{~d}^{9}\right)$ and nickel(II) $\left(3 \mathrm{~d}^{8}\right)$ complexes is the best understood in the $2 p-3 d$ family $[15-20,29]$. Strictly orthogonal arrangement of magnetic orbitals, metal $d \sigma$ and radical 
$\pi^{*}$, favors ferromagnetic coupling. In contrast, severe angular deformation around the coordination bond gives rise to an overlap between magnetic orbitals and accordingly antiferromagnetic interaction. We have proposed the M-O-N-C 2 torsion angle $|\varphi|$ as a handy metric to evaluate the orthogonal or overlapped $\mathrm{d} \sigma$ and radical $\pi^{*}$ orbitals $[19,24]$.

While exotic spin-transition/SCO systems are explored extensively [6,30], we are developing the $S=0 \rightleftarrows 2$ spin-transition system other than iron(II) complexes. Three examples have so far been known on the nickel(II)-bis(nitroxide) spin transition between $S_{\text {total }}=0 \rightleftarrows 2$. The reports on [Ni(phpyNO) $\left.2(X)_{2}\right]$ with $\mathrm{X}=\mathrm{Br}$ (1, Scheme 1 for the molecular structure) [31], Cl (2) [32], and NCS (3) [33] afforded a clue to a molecular design, where phpyNO stands for tert-butyl 5-phenyl-2-pyridyl nitroxide. A steric effect from anionic co-ligands may tune spin-transition temperature. Here, we will report the results of the $\mathrm{X}=\mathrm{NCO}$ derivative $(\mathbf{4})$.

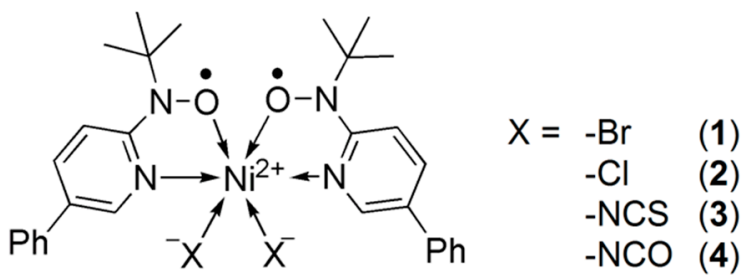

Scheme 1. Molecular formula of 1-4.

\section{Results}

\subsection{Structural Study}

Complex [Ni(phpyNO $\left.)_{2}(\mathrm{NCO})_{2}\right]$ (4) was synthesized by combining solutions of phpyNO and $\mathrm{Ni}\left(\mathrm{BF}_{4}\right)_{2}$ in the presence of NaNCO. The elemental, spectroscopic, and crystallographic analyses revealed the absence of any solvent molecules.

Single-crystal X-ray diffraction measurements on 4 were performed at 100, 200, 300, and $400 \mathrm{~K}$, and Figure 1a,b show the determined structures at 100 and $400 \mathrm{~K}$, respectively. The space group is orthorhombic Pna2 1 , and there is a unique molecule in an asymmetric unit. Although the molecular structure of highly related analogue 3 is quite similar, the space group is different [33]. It is probably because the intermolecular interaction regarding the thiocyanate sulfur atoms [34] plays a role of driving force in crystallization of 3 .

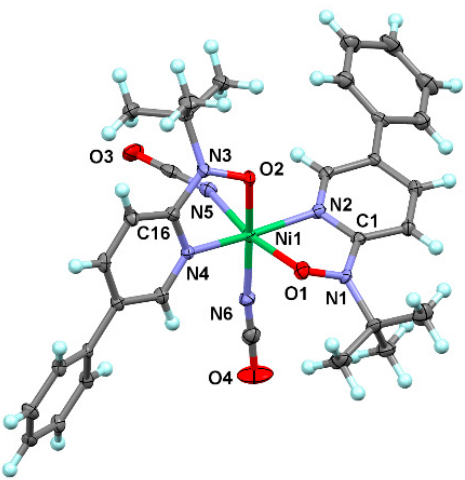

(a)

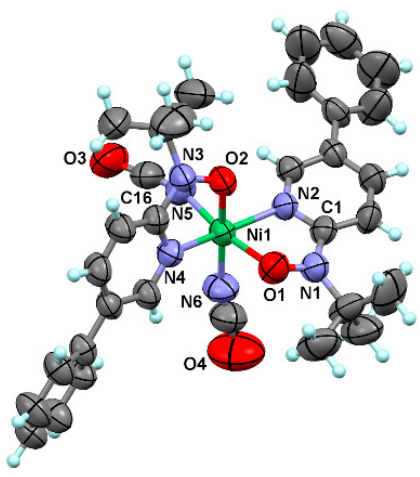

(b)

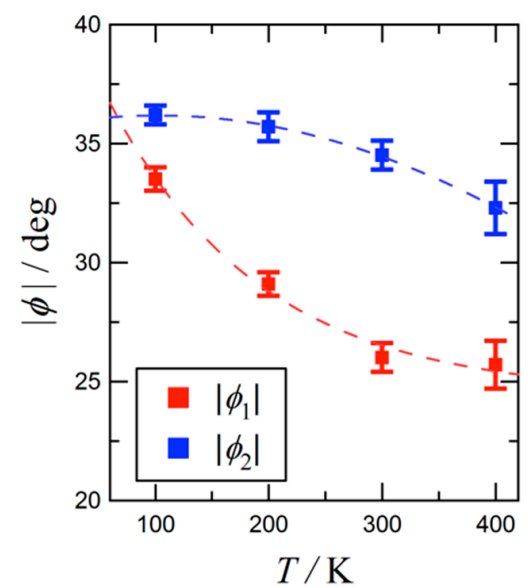

(c)

Figure 1. (a) X-ray crystal structure of 4 measured at $100 \mathrm{~K}$ and (b) $400 \mathrm{~K}$. Thermal ellipsoids are drawn at the $50 \%$ probability level. Selected atomic numbering is also shown. (c) Temperature dependences of torsion angles $(|\varphi|)$ for 4 . Broken lines are drawn for a guide to the eye. 
A $2 p-3 d-2 p$ triad was successfully constructed as a discrete molecule of 4 . The co-ligand $\mathrm{NCO}^{-}$is coordinated at a nitrogen atom. Each five-membered chelate ring involves a direct metal-radical bond. The two nitroxide oxygen atoms are located in a cis relation.

At $100 \mathrm{~K}$ (Figure 1a), the N1-O1 and N2-O3 bond lengths of 1.297(5) and 1.292(5) $\AA$ are typical of phpyNO complexes [19]. The Ni-O and Ni-N bond lengths vary in 1.985(4)-2.090(4) $\AA$. The octahedral coordination geometry of the nickel(II) ion indicates $S_{\mathrm{Ni}} 2^{+}=1$. The bond lengths and bond angles are almost unchanged on heating from $100 \mathrm{~K}$ to $400 \mathrm{~K}$. The coordination polyhedron was quantified with the SHAPE program [35]. In fact, the SHAPE measures to the ideal octahedron were 0.887, 0.867, 0.887 , and 0.869 for the structures at 100, 200,300, and $400 \mathrm{~K}$, respectively. The crystal field practically does not change in the entire temperature range. This feature is characteristic of the present transition materials (see below), in sharp contrast to the observation in conventional one-centered SCO materials.

On the other hand, the Ni1-O1-N1-C1 and Ni1-O2-N3-C16 torsion angles were reduced; $\varphi_{1}=33.5(5)^{\circ}$ and $\varphi_{2}=36.2(4)^{\circ}$ at $100 \mathrm{~K}$ vs. 25.7(10) and $32.3(11)^{\circ}$ at $400 \mathrm{~K}$ (Figure $\left.1 \mathrm{~b}\right)$. As Figure $1 \mathrm{c}$ displays, $\varphi$ monotonically decreases on heating. The change width is relatively narrow, in comparison with those of $\mathbf{1}$ and $\mathbf{2}$ [31,32].

\subsection{Magnetic Study}

Figure 2a displays the magnetic susceptibility result on 4 . The $\chi_{\mathrm{m}} T$ value was $1.04 \mathrm{~cm}^{3} \mathrm{~K} \mathrm{~mol}^{-1}$ at $400 \mathrm{~K}$, being still smaller than $1.75 \mathrm{~cm}^{3} \mathrm{~K} \mathrm{~mol}^{-1}$ as the spin-only value from one triplet and two doublet species. Furthermore, a positive slope remained at $400 \mathrm{~K}$. On cooling, the $\chi_{\mathrm{m}} T$ value decreased and approached an almost diamagnetic level. These findings indicate that the presence of considerable antiferromagnetic interaction. According to Okazawa's formalism [36], the critical torsion angle $\varphi_{\mathrm{c}}$ is $21(1)^{\circ}$, and any $\varphi$ values obtained here fell in the antiferromagnetic region. The magneto-structure relationship $[19,20,31,36]$ holds well for the present case.

(a)

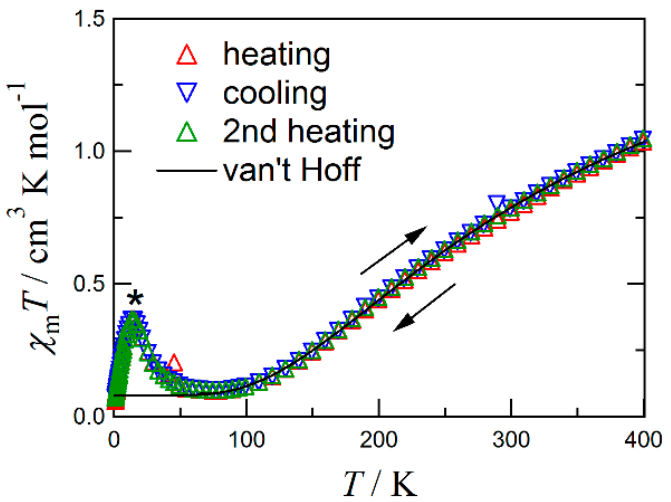

(b)

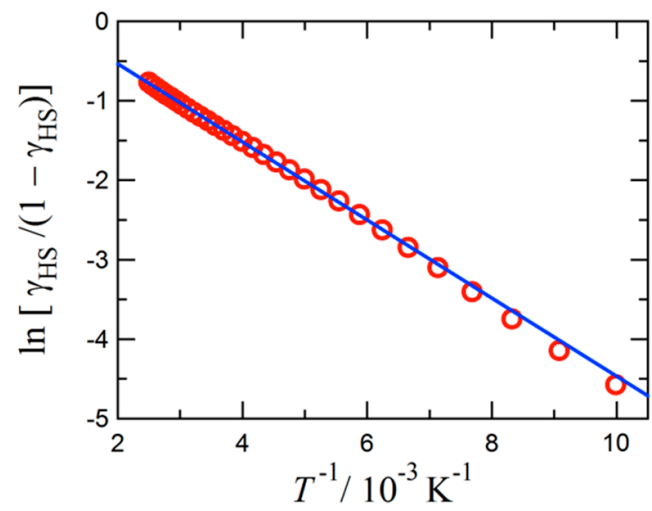

Figure 2. (a) The $\chi_{\mathrm{m}} T$ vs. $T$ plot for 4 . An asterisk indicates an impurity signal. (b) van't Hoff plot of the first heating data above $100 \mathrm{~K}$. The solid lines are calculated with the van't Hoff equation and optimized parameters (see the text). In (b) the intercept is $\Delta S / R=0.447$, and the slope is $-\Delta H / R=-492 \mathrm{~K}$, where $R$ is the gas constant.

An impurity peak appeared around $15 \mathrm{~K}$, but the impurity was experimentally inseparable from the specimen (Figure 2a). Probably it would be ascribable to layered or networked magnets based on nickel(II) hydroxides [37-39]. Fortunately, this signal occurs only in the lowest temperature region below ca. $50 \mathrm{~K}$, while the $\chi_{\mathrm{m}} T$ onset ascribable to 4 emerges above ca. $100 \mathrm{~K}$. The impurity signal hardly disturbs the magnetic analysis.

The magnetic data were analyzed quite similarly to that of 3 [33]. The structural study clarifies that the coordination structure is temperature dependent. The van Vleck analysis using an exchange constant is inappropriate. We found that the magnetic data of 4 obeyed the van't Hoff law (Equation (1)) 
(Figure 2b). The van't Hoff analysis is a common method to quantify SCO behavior in the absence of a cooperative effect $[40,41]$.

$$
\begin{gathered}
\gamma_{\mathrm{HS}}=\frac{1}{1+\exp \left[(\Delta H / R)\left(1 / T-1 / T_{1 / 2}\right)\right]} \\
\chi_{\mathrm{m}} T=C_{0} \gamma_{\mathrm{HS}}+C_{1}
\end{gathered}
$$

The experimental $\chi_{\mathrm{m}} T$ value was converted to $\gamma_{\mathrm{HS}}$, the molar HS fraction (Equation (2)). Parameters $C_{0}$ implies the Curie constants for the HS state, and $C_{1}$ that of the paramagnetic impurity. The optimized parameters are: $C_{0}=3.0(3) \mathrm{cm}^{3} \mathrm{~K} \mathrm{~mol}^{-1}, C_{1}=0.080(3) \mathrm{cm}^{3} \mathrm{~K} \mathrm{~mol}^{-1}, T_{1 / 2}=1100(300) \mathrm{K}$, the enthalpy change $\Delta H=4.1(1) \mathrm{kJ} \mathrm{mol}^{-1}$, and the entropy change $\Delta S=3.7(19) \mathrm{J} \mathrm{K}^{-1} \mathrm{~mol}^{-1}$. The fit curves reproduced the data well. The $C_{0}$ value is compatible with the spin-only value expected for the HS state $\left(S=2 ; 3.0 \mathrm{~cm}^{3} \mathrm{~K} \mathrm{~mol}^{-1}\right)$. The relatively small $C_{1}$ supports the sample purity. The large statistic error of $T_{1 / 2}$ is unavoidable because of only the onset $\chi_{\mathrm{m}} T$ data available. Although the $C_{0}$ parameter seems to be somewhat underestimated and $T_{1 / 2}$ overestimated, owing to a depopulation effect, 4 would display a possible thermal spin transition at $T_{1 / 2}>>400 \mathrm{~K}$.

\subsection{DFT Calculation Study}

The atomic coordinates of 4 experimentally determined at 100, 200, 300, and $400 \mathrm{~K}$ were subjected to density functional theory (DFT) calculation [42]. The self-consistent field (SCF) energies were computed using the unrestricted DFT theories and 6-311+G(2d,p) basis set. We chose B3LYP, PBE0, and TPSSh $[43,44]$ to check the functional dependence. Figure 3 shows the singlet-quintet energy gaps as a function of temperature. The ground state is singlet at any temperatures, and the gap tends to monotonically decrease, apparently toward null, with an increase of temperature. The PBE0 calculation underestimates the magnitude of the gap, while the TPSSh one overestimates, with respect to the B3LYP result. The three theories qualitatively gave the identical trend.

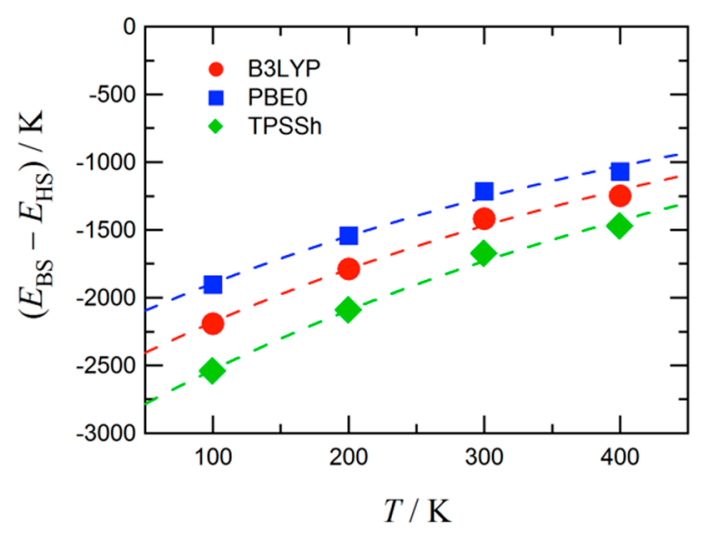

Figure 3. The energy gap between the broken symmetry singlet state $\left(E_{\mathrm{BS}}\right)$ and quintet state $\left(E_{\mathrm{HS}}\right)$.

The functional dependence is also shown. Broken lines are drawn for a guide to the eye.

Detailed energy level structures were computed with the B3LYP theory, and Figure 4 shows the results of the 100 and $400 \mathrm{~K}$ structures of 4 . For the $100 \mathrm{~K}$ form (Figure 4, left), the lowest state was singlet, depicted as $\downarrow-\uparrow \uparrow-\downarrow$ along the radical-Ni-radical array. The highest state was quintet, $\uparrow-\uparrow \uparrow-\uparrow$. The singlet-quintet gap was $-2196 \mathrm{~K}$. Two triplet states, $\uparrow-\uparrow \uparrow-\downarrow$ and $\downarrow-\uparrow \uparrow-\uparrow$, intervene them. The exchange couplings are antiferromagnetic on both sides. For the $400 \mathrm{~K}$ form (Figure 4, right), the ground state was also singlet, and the dominant antiferromagnetic behavior retained. However, the most important point is a weakened antiferromagnetic interaction. The singlet-quintet gap was reduced to $-1245 \mathrm{~K}$ (57\% of the corresponding value of the $100 \mathrm{~K}$ form). The energy gap to the first excited triplet state became narrow as $-323 \mathrm{~K}(37 \%$ of that of the $100 \mathrm{~K}$ form). The thermal energy at the temperatures of the magnetic experiments is comparable to this gap. These calculation results are entirely consistent with the magnetic study results. 


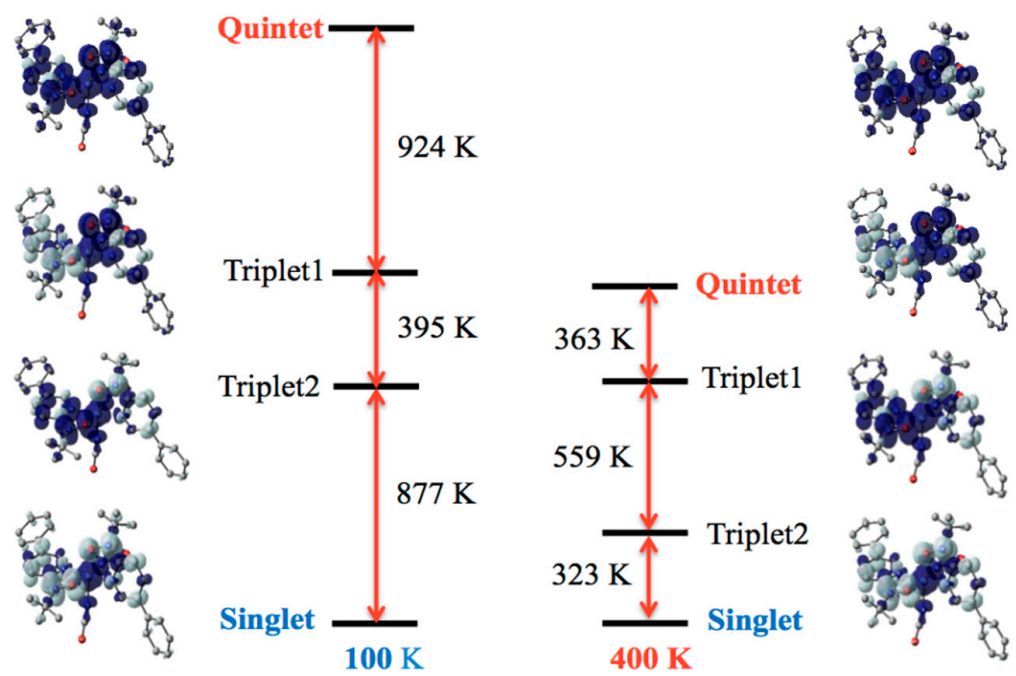

Figure 4. Diagram of the energy levels of the singlet, two triplet, and quintet states for the $100 \mathrm{~K}$ and $400 \mathrm{~K}$ forms of 4 . Molecules are shown with a spin density map superposed. $\mathrm{H}$ atoms are omitted. The positive (dark) and negative spin densities (light) are drawn with an isocontour of $0.002 \mathrm{e}^{-} \AA^{-3}$.

A definitive support for the structure-related exchange coupling switch was offered from geometry optimization results. The optimization was carried out with the B3LYP protocol on the 6-311+G(2d,p) basis set for $\mathrm{Ni}$ and $6-31+\mathrm{G}(\mathrm{d})$ basis set for other atoms. To reduce calculation cost, the peripheral tert-butyl and phenyl groups were replaced with methyl and hydrogen groups, respectively; namely methyl 2-pyridyl nitroxide (abbreviated as L) was applied as a model ligand. The optimized structures of $\left[\mathrm{NiL}_{2}(\mathrm{NCO})_{2}\right]$ are displayed in Figure $5 \mathrm{a}, \mathrm{b}$. The Ni-O-N-C $\mathrm{Cp}_{\mathrm{sp}} 2$ torsion angles of the diamagnetic state are $32.7^{\circ}$, whereas those of the $S_{\text {total }}=2$ state are $11.9^{\circ}$. They possess a two-fold symmetry. Although the conformation of the NCO groups varied during the energy minimization, it is safely concluded that intramolecular 2p-3d antiferromagnetic coupling favors a large torsion, while ferromagnetic coupling a small torsion. The calculation well reproduced the experimental values of the diamagnetic phase. However, the value of $11.9^{\circ}$ could not be experimentally observed even at $400 \mathrm{~K}$. In other words, the thermal energy of $400 \mathrm{~K}$ is insufficient to cause spin transition.

(a)

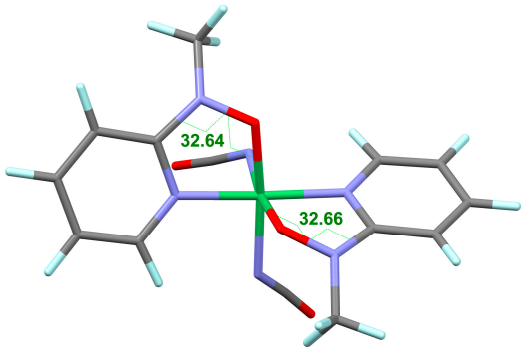

(c)

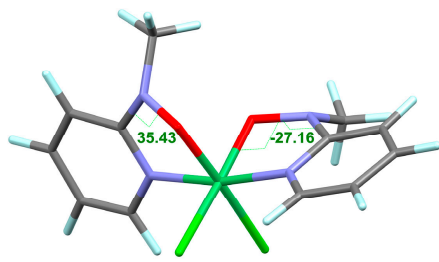

(b)

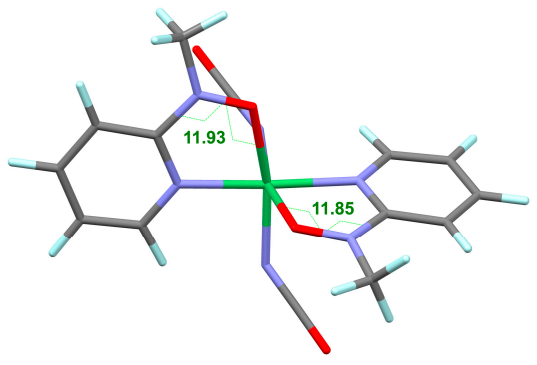

(d)

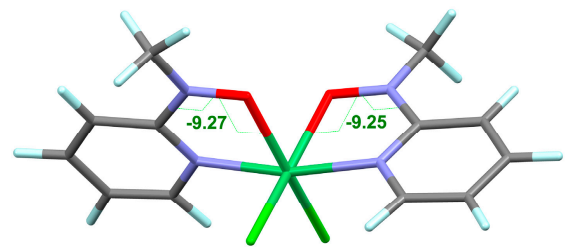

Figure 5. Optimized structures of model $2 p-3 d-2 p$ compounds: $\left[\mathrm{NiL}_{2}(\mathrm{NCO})_{2}\right]$ in the diamagnetic state (a) and the $S_{\text {total }}=2$ state $(\mathbf{b})$ and $\left[\mathrm{NiL}_{2} \mathrm{Cl}_{2}\right]$ in the diamagnetic state (c) and the $S_{\text {total }}=2$ state (d), where $\mathrm{L}$ stands for methyl 2-pyridyl nitroxide. The Ni-O-N-C $\mathrm{sp} 2$ torsion angles are indicated. Color codes: green, $\mathrm{Ni}$; black, $\mathrm{C}$; turquoise, $\mathrm{H}$; blue, $\mathrm{N}$; red, $\mathrm{O}$. 
To remove the conformational freedom in the co-ligands, another calculation was performed on a model compound $\left[\mathrm{NiL}_{2} \mathrm{Cl}_{2}\right]$. The geometries were optimized for the diamagnetic and $S_{\text {total }}=2$ states on the same calculation level (Figure $5 \mathrm{c}, \mathrm{d}$, respectively). The former has $\varphi=35.4$ and $-27.2^{\circ}$, while the latter has $\varphi=-9.3^{\circ}$. The experimental values of 2 are 38.9(2) and -29.2(2) at $85 \mathrm{~K}$ and 25.8(3) and $13.0(4)$ at $400 \mathrm{~K}$ [32]. In that case, the $85 \mathrm{~K}$ and $400 \mathrm{~K}$ structures are concluded to belong to the LS and HS phases, respectively. The calculation well reproduced the experimental values for the diamagnetic phase in particular. The sign of $\varphi$ means a chirality of the torsional direction. The absolute values are important for the orbital overlap, but it must be pointed out that the same and different signs indicate "conrotatory" and "disrotatory" twisting directions, respectively, in a molecule. The DFT calculation reproduced as well such observations in the diamagnetic state.

\section{Discussion}

The nickel(II)-radical exchange coupling parameter varies in a wide range, actually $2 J / k_{\mathrm{B}}=$ $+409 \mathrm{~K}$ [19] to $-1400 \mathrm{~K}$ [45], and is very sensitive to the overlap between the nickel(II) and radical magnetic orbitals. Thanks to this, the unique spin transition materials are realized. The novelty of the present spin transition mechanism resides in the ferro- and antiferromangetic exchange coupling switch, corresponding to the HS and LS phases, respectively.

Now let us move to discuss: What is the driving force of the torsional deformation found in 4 ? Why both wings synchronously move?

Figure 6a summarizes the calculation results on 1-4 [31-33]. In sharp contrast to the results on 3 and 4, the spin multiplicity of 1 and 2 was calculated to be $\mathrm{HS}$ at $400 \mathrm{~K}$ with the singlet-quintet energy gaps were +141 and $+102 \mathrm{~K}$ for $\mathbf{1}$ and $\mathbf{2}$, respectively. They are spin-transition materials due to the exchange coupling switch. On the other hand, the thermal energy is insufficient for spin transition even at $400 \mathrm{~K}$ for 3 and 4 . Overall, the four compounds are documented in a common phase diagram, as illustrated in Figure $6 \mathrm{~b}$. The critical temperature $T_{1 / 2}$ is defined by the level crossing point. Compounds 3 and 4 exhibited an indication of a possible spin-transition, as a result of $T_{1 / 2}$ outside of the temperature window of conventional magnetic measurements. Even if the temperature is elevated above $T_{1 / 2}$, the magnetic susceptibility did not reach the HS limit, but approached the paramagnetic limit, owing to depopulation from the HS state.

(a)

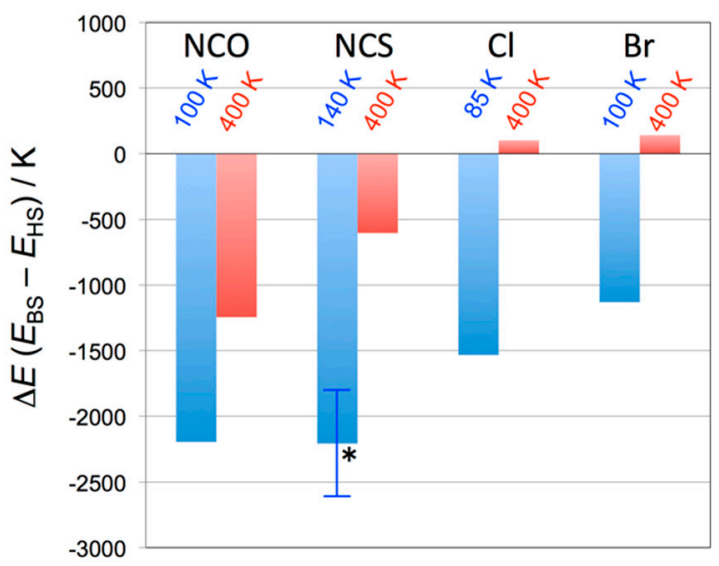

(b)

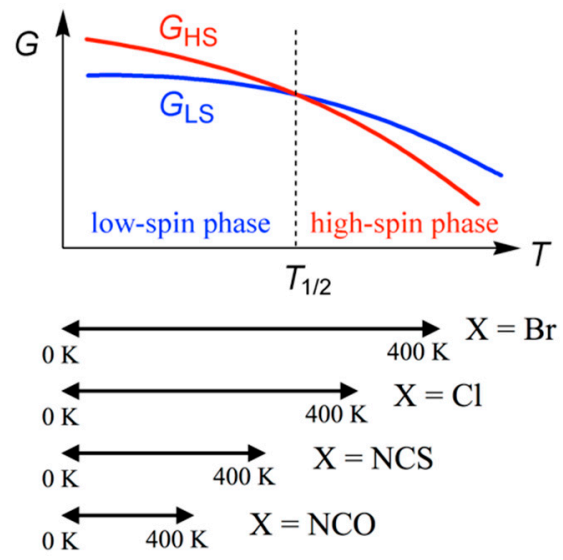

Figure 6. (a) Temperature dependence of the energy gap between the broken-symmetry singlet state (BS) and quintet state (HS) on the determined structures of $4(X=N C O), 3(\mathrm{NCS}), 2(\mathrm{Cl}), 1$ (Br). The temperatures of structure determination are noted. An asterisk indicates an averaged value of the two independent molecules. For comparison on the same level, the data of 2 were updated as $\Delta E / k_{\mathrm{B}}=-1533$ and $+102 \mathrm{~K}$ at $T=85$ and $400 \mathrm{~K}$, respectively. (b) A schematic Gibbs energy diagram together with the experimental temperature windows for spin-transition materials 1-4. 
We have to state briefly the $T_{1 / 2}$ order: $\mathbf{1}<\mathbf{2}<\mathbf{3}<\mathbf{4}$. This chemical trend can be explained in terms of the steric effects from the co-ligands [33]. The order of the van der Waals radii is $r(\mathrm{~N})<r(\mathrm{Cl})<$ $r(\mathrm{Br})$ [46], and the ligating atom mainly affects the steric congestion in the first coordination sphere. The terminal sulfur and oxygen atoms may play an auxiliary role. Small co-ligands can accommodate out-of-plane displacement of adjacent ligating atoms (i.e., nitroxide oxygen atoms), giving rise to stabilization of the LS state and accordingly a high-temperature shift of $T_{1 / 2}$.

All the compounds exhibited a single-crystal-to-single-crystal transition, as often found in organic-based spin-transition materials [47]. The enthalpy change supplying the atomic dislocation energy is regulated by the entropy change $\left(T_{1 / 2} \Delta_{\operatorname{tr}} S=\Delta_{\operatorname{tr}} H\right)$, which is generally small. The entropy due to the vibrational contribution is negligible because the structural change is merely the torsional deformation in 1-4, in comparison with those of the bond length changes in the conventional one-centered SCO compounds like iron(II) complexes. Consequently, the spin entropy change suffices the enthalpy change of the spin transition accompanied by the small structural transition. In short, the spin transition of the present series seems to be entropy-driven $[48,49]$. The Ni-O-N-C 2 angular deformations in 1-4 are always synchronized on both wings, and every interaction tends to alter from ferro- to antiferromagnetic on lowering temperature, because the spin multiplicity could be minimized (in this case, $S_{\text {total }}=0$ ). This notion also holds for the result on a spin-transition copper(II)-bis(nitroxide) analogue, $\left[\mathrm{Cu}(\mathrm{phpyNO})_{2}\left(\mathrm{H}_{2} \mathrm{O}\right)_{2}\right]\left(\mathrm{BF}_{4}\right)_{2}$ [50]. In that case, no synchronous transition occurs between the $S_{\text {total }}=3 / 2$ and $1 / 2$ states. Only one side deformation is enough for minimization of $S_{\text {total }}$.

There have been several reports on spin-transition phenomena in copper(II)-radical systems. Okazawa et al. reported the spin transition of $\mathrm{Cu}^{2+}$-nitroxide compounds, and the mechanism is quite similar to the present $\mathrm{Ni}^{2+}$ case $[50,51]$. Namely, the $\mathrm{Cu}-\mathrm{O}-\mathrm{N}-\mathrm{C}_{\mathrm{sp}} 2$ angular deformation causes the exchange coupling switch. On the other hand, Ovcharenko et al. reported the spin-transition $\mathrm{Cu}^{2+}$-nitroxide compounds [52,53], and the mechanism involves a switch of the role of axial and equatorial coordinations [54]. Rey et al. reported another type of the spin-transition $\mathrm{Cu}^{2+}$-nitroxide materials [55], where the coordination environment is changed between a square pyramid and a trigonal bipyramid. In contrast, our group focused on octahedral nickel(II) complexes. A coupling switch takes place at any coordination sites, axial or equatorial. Rey et al. named a "pseudo-spin-transition" material that shows a switch between strong and weak ferromagnetic couplings. Thus, this article is supposed to report another example of a "pseudo-spin-transition" material that shows a switch between strong and moderate antiferromagnetic couplings.

\section{Materials and Methods}

The following procedure of the preparation of 4 is typical. An acetone solution $(1.0 \mathrm{~mL})$ containing phpyNO [19] $(48.4 \mathrm{mg} ; 0.201 \mathrm{mmol})$ was combined with a water $(0.60 \mathrm{~mL})-$ methanol $(0.40 \mathrm{~mL})$ mixed solution containing $\mathrm{Ni}\left(\mathrm{BF}_{4}\right)_{2} \cdot 6 \mathrm{H}_{2} \mathrm{O}(35.0 \mathrm{mg} ; 0.103 \mathrm{mmol})$ and $\mathrm{NaNCO}(13.8 \mathrm{mg} ; 0.212 \mathrm{mmol})$ at room temperature. After two days black rectangle-shaped crystals of 4 were formed, which were collected on a filter, washed, and dried. The yield was $36.3 \mathrm{mg}(0.0581 \mathrm{mmol} ; 58 \%)$. Mp. $196{ }^{\circ} \mathrm{C}$ (dec.). IR (neat, attenuated total reflection) 3065, 2985, 2195, 1454, 1313, 1258, 1182, 1012, 764, $692,610 \mathrm{~cm}^{-1}$. Anal. Calcd. for $\mathrm{C}_{32} \mathrm{H}_{34} \mathrm{~N}_{6} \mathrm{NiO}_{4}$ : C, 61.46; H, 5.48; N, 13.44\%. Found: C, 61.63; H, 5.64; N, $13.52 \%$.

$X$-ray diffraction data of a single crystal of 4 were recorded on a Rigaku Saturn70 CCD diffractometer using graphite monochromatized Mo K $\alpha$ radiation $(\lambda=0.71073 \AA)$. The structures were solved in the CRYSTALSTRUCTURE application [56], and the parameters were refined in the SHELXL module [57]. Hydrogen atoms were located at calculated positions. Important crystal data are listed in Table 1. CCDC numbers 2018891 and 2018892 for the structures at 100 and $400 \mathrm{~K}$, respectively.

Magnetic susceptibilities of polycrystalline 4 were acquired on a Quantum Design MPMS XL-7 SQUID magnetometer (San Diego, CA, USA). Temperature was scanned from 1.8 to $400 \mathrm{~K}$ at a constant magnetic field of 0.5 T. The diamagnetic susceptibility was calculated from Pascal's constant [58].

Density functional theory (DFT) calculations were carried out on the Gaussian16 Revision C.01 [59]. The broken symmetry method [42] was applied. For analyzing energy level structures of 
4, the self-consistent field energies were calculated with the experimentally-determined coordinates. For geometrical optimization, a tight conversion was applied from the experimental coordinates as a starting structure.

Table 1. Selected crystallographic parameters of 4 .

\begin{tabular}{|c|c|c|}
\hline Compound & \multicolumn{2}{|c|}{$\left[\mathrm{Ni}(\mathrm{phpyNO})_{2}(\mathrm{NCO})_{2}\right](4)$} \\
\hline$T / K$ & 100 & 400 \\
\hline Formula, formula weight & \multirow{3}{*}{\multicolumn{2}{|c|}{$\begin{array}{c}\mathrm{C}_{32} \mathrm{H}_{34} \mathrm{~N}_{6} \mathrm{NiO}_{4}, 625.36 \\
\text { orthorhombic } \\
\text { Pna } 2_{1}\end{array}$}} \\
\hline Crystal system & & \\
\hline Space group & & \\
\hline$a / \AA$ & $19.489(4)$ & $19.727(9)$ \\
\hline$b / \AA$ & $8.992(2)$ & $9.409(4)$ \\
\hline$c / \AA$ & $17.316(4)$ & $17.217(7)$ \\
\hline$V / \AA^{3}$ & $3034.5(11)$ & $3196(2)$ \\
\hline Z & 4 & 4 \\
\hline$d_{\text {calcd }} / \mathrm{g} \cdot \mathrm{cm}^{-3}$ & 1.369 & 1.300 \\
\hline$\mu(\mathrm{MoK} \alpha) / \mathrm{mm}^{-1}$ & 0.686 & 0.652 \\
\hline No. of unique reflections & 6948 & 7227 \\
\hline$R(F)(I>2 \sigma(I))^{\mathrm{a}}$ & 0.0525 & 0.0805 \\
\hline$w R\left(F^{2}\right)$ (all reflections) ${ }^{b}$ & 0.0989 & 0.1932 \\
\hline Goodness-of-fit parameter & 1.054 & 1.155 \\
\hline
\end{tabular}

\section{Conclusions}

When the singlet-quintet energy gap is relatively small, there is a chance of spin transition. After overviewing the results on $\left[\mathrm{Ni}(\text { phpyNO })_{2}(\mathrm{X})_{2}\right](\mathrm{L}=\mathrm{Br}, \mathrm{Cl}, \mathrm{NCS}, \mathrm{NCO})$, the magnetic behavior is described in a common phase diagram. The $\mathrm{Br}$ and $\mathrm{Cl}$ compounds undergo the energy level crossing of the HS/LS states and behave as a spin-transition material. On the other hand, the NCS and NCO compounds do not in a conventional experimental temperature range. The HS/LS phases originate directly from the intramolecular $2 \mathrm{p}-3 \mathrm{~d}$ ferro-/antiferromagnetic exchange couplings.

The present solid-state/solid-state structural transition, or more likely crossover, involves a very slight torsional deformation around the coordination bond. Thus, the preset scenario can be regarded as a novel mechanism operative in multi-centered SCO. The spin state is regulated by antiferro-/ferromagnetic balance in multi-centered systems, in place of the aufbau/Hund balance in one-centered systems. The aufbau principle works in gapped d-orbitals caused by a ligand field as well as in gapped bonding and antibonding molecular orbitals caused by interaction between magnetic orbitals.

Finally, we have to emphasize that $J$ is a variable of $T$ in the analysis of the magnetic data. The single-point $X$-ray crystal structure analysis cannot reveal a hidden structural transition, but combining detailed works from structural chemistry and magnetochemistry can solve such problems.

Author Contributions: Y.K. participated in the preparation, characterization, magnetic measurements, and DFT calculation. T.I. supervised the research and wrote the paper. Both authors have read and agreed to the published version of the manuscript.

Funding: This research was financially supported from KAKENHI (JSPS/20K21170).

Conflicts of Interest: The authors declare no competing financial interest.

\section{References}

1. Gütlich, P.; Goodwin, H.A. (Eds.) Spin Crossover in Transition Metal Compounds I, II, and III; Springer: Berlin, Germany, 2004.

2. Halcrow, M.A. (Ed.) Spin-Crossover Materials: Properties and Applications; John Wiley \& Sons, Inc.: Oxford, UK, 2013. 
3. Molnár, G.; Rat, S.; Salmon, L.; Nicolazzi, W.; Bousseksou, A. Spin Crossover Nanomaterials: From Fundamental Concepts to Devices. Adv. Mater. 2018, 30, 1703862. [CrossRef] [PubMed]

4. Coronado, E. Molecular magnetism: From chemical design to spin control in molecules, materials and devices. Nat. Rev. Mater. 2020, 5, 87-104. [CrossRef]

5. Kumar, K.S.; Ruben, M. Emerging trends in spin crossover (SCO) based functional materials and devices. Coord. Chem. Rev. 2017, 346, 176-205. [CrossRef]

6. Sato, O.; Tao, J.; Zhang, Y.Z. Control of magnetic properties through external stimuli. Angew. Chem. Int. Ed. 2007, 46, 2152-2187. [CrossRef]

7. Ratera, I.; Veciana, J. Playing with organic radicals as building blocks for functional molecular materials. Chem. Soc. Rev. 2012, 41, 303-349. [CrossRef]

8. Iwamura, H. What role has organic chemistry played in the development of molecule-based magnets? Polyhedron 2013, 66, 3-14. [CrossRef]

9. Aromí, G.; Real, J.A. Special Issue "Spin Crossover (SCO) Research". Magnetochemistry 2016, 2, 28. [CrossRef]

10. Takahashi, K. Special Issue "Spin-Crossover Complexes". Inorganics 2018, 6, 32. [CrossRef]

11. Kitazawa, T. Special Issue "Synthesis and Applications of New Spin Crossover Compounds". Crystals 2019, 9, 382. [CrossRef]

12. Hayami, S.; Holmes, S.M.; Halcrow, M.A. Themed Issue "Spin-State Switches in Molecular Materials Chemistry". J. Mater. Chem. C 2015, 3, 7767. [CrossRef]

13. Kimura, A.; Ishida, T. Spin-crossover temperature predictable from DFT calculation for iron(II) complexes with 4-substituted pybox and related heteroaromatic ligands. ACS Omega 2018, 3, 6737-6747. [CrossRef] [PubMed]

14. Kashiro, A.; Kohno, W.; Ishida, T. Odd-Even Effect on the Spin-Crossover Temperature in Iron (II) Complex Series Involving an Alkylated or Acyloxylated Tripodal Ligand. Inorg. Chem. 2020, 59, 10163-10171. [CrossRef]

15. Caneschi, A.; Gatteschi, D.; Sessoli, R.; Rey, P. Toward molecular magnets: The metal-radical approach. Acc. Chem. Res. 1989, 22, 392-398. [CrossRef]

16. Meng, X.; Shi, W.; Cheng, P. Magnetism in one-dimensional metal-nitronyl nitroxide radical system. Coord. Chem. Rev. 2019, 378, 134-150. [CrossRef]

17. Osanai, K.; Okazawa, A.; Nogami, T.; Ishida, T. Strong Ferromagnetic Exchange Couplings in Copper(II) and Nickel(II) Complexes with a Paramagnetic Tridentate Chelate Ligand, 2,2'-Bipyridin-6-yl tert-Butyl Nitroxide. J. Am. Chem. Soc. 2006, 128, 14008-14009. [CrossRef] [PubMed]

18. Okazawa, A.; Nogami, T.; Ishida, T. tert-Butyl 2-Pyridyl Nitroxide Available as a Paramagnetic Chelate Ligand for Strongly Exchange-Coupled Metal-Radical Compounds. Chem. Mater. 2007, 19, 2733-2735. [CrossRef]

19. Okazawa, A.; Nagaichi, Y.; Nogami, T.; Ishida, T. Magneto-structure relationship in copper(II) and nickel(II) complexes chelated with stable tert-butyl 5-phenyl-2-pyridyl nitroxide and related radicals. Inorg. Chem. 2008, 47, 8859-8868. [CrossRef] [PubMed]

20. Okazawa, A.; Nogami, T.; Ishida, T. Strong intramolecular ferromagnetic couplings in nickel(II) and copper(II) complexes chelated with tert-butyl 5-methoxy-2-pyridyl nitroxide. Polyhedron 2009, 28, 1917-1921. [CrossRef]

21. Kawakami, H.; Tonegawa, A.; Ishida, T. A designed room-temperature triplet ligand from pyridine-2,6-diyl bis(tert-butyl nitroxide). Dalton Trans. 2016, 45, 1306-1309. [CrossRef]

22. Homma, Y.; Okazawa, A.; Ishida, T. Ground triplet pyrimidine-4,6-diyl bis(tert-butyl nitroxide) as a paramagnetic building block for metal-organic frameworks. Tetrahedron Lett. 2013, 54, 3120-3123. [CrossRef]

23. Okazawa, A.; Terakado, Y.; Ishida, T.; Kojima, N. A triplet biradical with double bidentate sites based on tert-butyl pyridyl nitroxide as a candidate for strong ferromagnetic couplers. New J. Chem. 2018, 42, 17874-17878. [CrossRef]

24. Ishida, T.; Murakami, R.; Kanetomo, T.; Nojiri, H. Magnetic study on radical-gadolinium(III) complexes. Relationship between the exchange coupling and coordination structure. Polyhedron 2013, 66, 183-187. [CrossRef]

25. Kanetomo, T.; Ishida, T. Strongest exchange coupling in gadolinium(III) and nitroxide coordination compounds. Inorg. Chem. 2014, 53, 10794-10796. [CrossRef] [PubMed]

26. Kanetomo, T.; Yoshitake, T.; Ishida, T. Strongest Ferromagnetic Coupling in Designed Gadolinium(III)Nitroxide Coordination Compounds. Inorg. Chem. 2016, 55, 8140-8146. [CrossRef] [PubMed] 
27. Kanetomo, T.; Kihara, T.; Miyake, A.; Matsuo, A.; Tokunaga, M.; Kindo, K.; Nojiri, H.; Ishida, T. Giant Exchange Coupling Evidenced with a Magnetization Jump at $52 \mathrm{~T}$ for a Gadolinium-Nitroxide Chelate. Inorg. Chem. 2017, 56, 3310-3314. [CrossRef]

28. Baker, M.L.; Tanaka, T.; Murakami, R.; Ohira-Kawamura, S.; Nakajima, K.; Ishida, T.; Nojiri, H. Relationship between torsion and anisotropic exchange coupling in a $\mathrm{Tb}^{\mathrm{III}}$-radical-based single-molecule magnet. Inorg. Chem. 2015, 54, 5732-5738. [CrossRef]

29. Kahn, O.; Prins, R.; Reedijk, J.; Thompson, J.S. Orbital symmetries and magnetic interaction between copper (II) ions and the $o$-semiquinone radical. Magnetic studies of (di-2-pyridylamine)(3,5-di-tert-butyl-o-semiquinonato) copper(II) perchlorate and bis(bis(3,5-di-tert-butyl-o-semiquinonato)copper(II)). Inorg. Chem. 1987, 26, 3557-3561. [CrossRef]

30. Olguín, J. Unusual metal centres/coordination spheres in spin crossover compounds. Coord. Chem. Rev. 2020, 407, 213148. [CrossRef]

31. Kyoden, Y.; Homma, Y.; Ishida, T. High-Spin and Incomplete Spin-Crossover Polymorphs in Doubly Chelated [Ni(L) ${ }_{2} \mathrm{Br}_{2}$ ] (L = tert-Butyl 5-Phenyl-2-pyridyl Nitroxide). Inorg. Chem. 2019, 58, 10743-10755. [CrossRef]

32. Homma, Y.; Ishida, $\mathrm{T}$. A new $\mathrm{S}=0 \rightleftarrows \mathrm{S}=2$ "Spin-crossover" scenario found in a Nickel(II) Bis(nitroxide) system. Chem. Mater. 2018, 30, 1835-1838. [CrossRef]

33. Kyoden, Y.; Ishida, T. An indication of spin-transition accompanied by an order-disorder structural transformation in [Ni(phpyNO) $\left.{ }_{2}(\mathrm{NCS})_{2}\right]$ (phpyNO = tert-butyl 5-phenyl-2-pyridyl nitroxide). RSC Adv. 2020, 10, 16009-16015. [CrossRef]

34. Guionneau, P.; Marchivie, M.; Bravic, G.; Letard, J.-F.; Chasseau, D. Structural Aspects of Spin Crossover. Example of the $\left[\mathrm{Fe}^{\mathrm{II}} \mathrm{L}_{\mathrm{n}}(\mathrm{NCS})_{2}\right]$ Complexes. Top. Curr. Chem. 2004, 234, 97-128.

35. Lluncll, M.; Casanova, D.; Circra, J.; Bofill, J.M.; Alcmany, P.; Alvarez, S.; Pinsky, M.; Avnir, D. SHAPE, v2.1; University of Barcelona: Barcelona, Spain, 2005.

36. Okazawa, A. Magneto-Structural Relationship on Strong Exchange Interactions between Chelating Nitroxide Radical and Transition-Metal Spins. IOP Conf. Ser. Mater. Sci. Eng. 2017, 202, 012002. [CrossRef]

37. Taibi, M.; Ammar, S.; Jouini, N.; Fiévet, F.; Molinié, P.; Drillon, M. Layered nickel hydroxide salts: Synthesis, characterization and magnetic behaviour in relation to the basal spacing. J. Mater. Chem. 2002, 12, 3238-3244. [CrossRef]

38. Kurmoo, M.; Day, P.; Derory, A.; Estournes, C.; Poinsot, R.; Stead, M.J.; Kepert, C.J. 3D Long-Range Magnetic Ordering in Layered Metal-Hydroxide Triangular Lattices 25 A Apart. J. Solid State Chem. 1999, 145, 452-459. [CrossRef]

39. Hall, D.S.; Lockwood, D.J.; Bock, C.; MacDougall, B.R. Nickel hydroxides and related materials: A review of their structures, synthesis and properties. Proc. R. Soc. A Math. Phys. Eng. Sci. 2015, 471, 20140792. [CrossRef]

40. Kahn, O. Molecular Magnetism; VCH: New York, NY, USA, 1993; pp. 53-69.

41. Boca, R. (Ed.) Theoretical Foundations of Molecular Magnetism: Current Methods in Inorganic Chemistry; Elsevier: Amsterdam, The Netherlands, 1999; Volume 1, pp. 541-563.

42. Noodleman, L. Valence bond description of antiferromagnetic coupling in transition metal dimers. J. Chem. Phys. 1981, 74, 5737-5743. [CrossRef]

43. Cramer, C.J.; Truhlar, D.G. Density functional theory for transition metals and transition metal chemistry. Phys. Chem. Chem. Phys. 2009, 11, 10757-10816. [CrossRef]

44. Pantazis, D.A. Assessment of Double-Hybrid Density Functional Theory for Magnetic Exchange Coupling in Manganese Complexes. Inorganics 2019, 7, 57. [CrossRef]

45. Ito, S.; Ishida, T. Practically Diamagnetic Macrocycle Consisting of Nickel-Biradical Heterospins with the Largest Out-of-Plane Torsion at Coordination Bonds. Chem. Lett. 2020, 49, 1062-1065. [CrossRef]

46. Bondi, A. Van der Waals volumes and radii. J. Phys. Chem. 1964, 68, 441-451. [CrossRef]

47. Ishida, T. Moving Molecules in Crystalline Solids: Gradual Structure Transition and Spin Transition/Crossover. IOP Conf. Ser. Mater. Sci. Eng. 2019, 515, 12001. [CrossRef]

48. Adams, D.M.; Dei, A.; Rheingold, A.L.; Hendrickson, D.N. Bistability in the [Co ${ }^{\mathrm{II}}$ (semiquinonate) 2 ] to [Co ${ }^{\mathrm{III}}$ (catecholate)(semiquinonate)] valence-tautomeric conversion. J. Am. Chem. Soc. 1993, 115, 8221-8229. [CrossRef] 
49. Letard, J.-F.; Real, J.A.; Moliner, N.; Gaspar, A.B.; Capes, L.; Cador, O.; Kahn, O. Light Induced Excited Pair Spin State in an Iron(II) Binuclear Spin-Crossover Compound. J. Am. Chem. Soc. 1999, 121, 10630-10631. [CrossRef]

50. Okazawa, A.; Ishida, T. Spin-Transition-Like Behavior on One Side in a Nitroxide-Copper(II)-Nitroxide Triad System. Inorg. Chem. 2010, 49, 10144-10147. [CrossRef] [PubMed]

51. Okazawa, A.; Hashizume, D.; Ishida, T. Ferro- and Antiferromagnetic Coupling Switch Accompanied by Twist Deformation around the Copper(II) and Nitroxide Coordination Bond. J. Am. Chem. Soc. 2010, 132, 11516-11524. [CrossRef] [PubMed]

52. Ovcharenko, V.; Fokin, S.; Chubakova, E.; Romanenko, G.; Bogomyakov, A.; Dobrokhotova, Z.; Lukzen, N.; Morozov, V.; Petrova, M.; Petrova, M.; et al. A Copper-Nitroxide Adduct Exhibiting Separate Single Crystal-to-Single Crystal Polymerization-Depolymerization and Spin Crossover Transitions. Inorg. Chem. 2016, 55, 5853-5861. [CrossRef]

53. Fedin, M.V.; Verber, S.L.; Bagryanskaya, E.; Ovcharenko, V.I. Electron Paramagnetic Resonance of Switchable Copper-Nitroxide-Based Molecular Magnets: An Indispensable Tool for Intriguing Systems. Coord. Chem. Rev. 2015, 289, 341-356. [CrossRef]

54. Lanfranc de Panthou, F.; Belorizky, E.; Calemczuk, R.; Luneau, D.; Marcenat, C.; Ressouche, E.; Turek, P.; Rey, P. A New Type of Thermally Induced Spin Transition Associated with an Equatorial $\leftrightarrow$ Axial Conversion in a Copper(II)-Nitroxide Cluster. J. Am. Chem. Soc. 1995, 117, 11247-11253. [CrossRef]

55. Lanfranc de Panthou, F.; Luneau, D.; Musin, R.; Öhrström, L.; Grand, A.; Turek, P.; Rey, P. Spin-Transition and Ferromagnetic Interactions in Copper(II) Complexes of a 3-Pyridyl-Substituted Imino Nitroxide. Dependence of the Magnetic Properties upon Crystal Packing. Inorg. Chem. 1996, 35, 3484-3491. [CrossRef]

56. Crystal Structure; Version 4.2; Rigaku/MSC: The Woodlands, TX, USA, 2010-2015.

57. Sheldrick, G.M. Crystal structure refinement with SHELXL. Acta Crystallogr. Sect. C Struct. Chem. 2015, 71, 3-8. [CrossRef] [PubMed]

58. Bain, G.A.; Berry, J.F. Diamagnetic Corrections and Pascal's Constants. J. Chem. Educ. 2008, 85, 532-536. [CrossRef]

59. Frisch, M.J.; Trucks, G.W.; Schlegel, H.B.; Scuseria, G.E.; Robb, M.A.; Cheeseman, J.R.; Scalmani, G.; Barone, V.; Petersson, G.A.; Nakatsuji, H.; et al. Gaussian 16, Revision C.01; Gaussian Inc.: Wallingford, CT, USA, 2019.

Sample Availability: Not available.

(C) 2020 by the authors. Licensee MDPI, Basel, Switzerland. This article is an open access article distributed under the terms and conditions of the Creative Commons Attribution (CC BY) license (http://creativecommons.org/licenses/by/4.0/). 